\title{
Failure to replicate the internal structure of Greek- specific thalassemia quality of life instrument in adult thalassemia patients in Sabah
}

This article was published in the following Dove Press journal:

Patient Preference and Adherence

22 February 2016

Number of times this article has been viewed

\author{
Thamron Keowmani' \\ Lily Wong Lee Lee ${ }^{2}$ \\ 'Clinical Research Centre, \\ ${ }^{2}$ Hematology Unit, Queen Elizabeth \\ Hospital, Kota Kinabalu, Sabah, \\ Malaysia
}

Purpose: To study the validity and reliability of the Malay version of the Specific Thalassemia Quality of Life Instrument (STQOLI) in Sabah's adult thalassemia patients.

Patients and methods: This cross-sectional study was done at Thalassemia Treatment Centre, Queen Elizabeth Hospital in Sabah, Malaysia. Eighty-two adult thalassemia patients who fulfilled the inclusion and exclusion criteria were conveniently selected for participation in the study. The English version of STQOLI was translated into Malay by using forward and back translations. The content of the questionnaire was validated by the chief hematologist of the hospital. The construct validity of the 40 -item questionnaire was assessed by principal component analysis with varimax rotation and the scale reliability was assessed by Cronbach's alpha.

Results: The study failed to replicate the internal structure of the Greek STQOLI. Instead, 12 factors have been identified from the exploratory factor analysis, which accounted for $72.2 \%$ of the variance. However, only eight factors were interpretable. The factors were iron chelation pump impact, transfusion impact, time spent on treatment and its impact on work and social life, sex life, side effects of treatment, cardiovascular problems, psychology, and iron chelation pill impact. The overall scale reliability was 0.913 .

Conclusion: This study was unable to replicate the internal structure of the Greek STQOLI in Sabah's adult thalassemia patients. Instead, a new structure has emerged that can be used as a guide to develop a questionnaire specific for adult thalassemia patients in Sabah. Future research should focus on the eight factors identified from this study.

Keywords: STQOLI, validity, reliability, Malay, transfusion

\section{Introduction}

Beta thalassemia, an inherited blood disorder, is most common in persons of Mediterranean, African, and Southeast Asian descent. ${ }^{1}$ In Malaysia, the prevalence of the heterozygous carriers for the disease is reported to be about $4.5 \%{ }^{2}$ The Malaysian Thalassemia Registry 2009 shows that one-fourth of the registered thalassemia patients are from the east Malaysia state of Sabah. ${ }^{3}$ And it was estimated that over 1,000 cases are transfusion-dependent beta thalassemia patients. ${ }^{4}$

Beta thalassemia is a serious life-limiting condition ${ }^{5}$ that not only affects patients' physical functioning but also their emotional functioning, social functioning, and school functioning, leading to impaired health-related quality of life (HRQOL) of the patients. ${ }^{6}$ HRQOL is an important dimension of care $^{7}$ and can be seen as a way for assessment of patients' perspectives about their disease and related treatments, their perceived needs for health care and their preference for treatment and disease outcomes. $^{8}$
Correspondence: Thamron Keowman Clinical Research Centre, Queen Elizabeth Hospital, 88586 Kota Kinabalu Sabah, Malaysia

Tel +6088517555

Fax +6088211906

Email thmrnkwmn@gmail.com (c) (1) (2) 2016 Keowmani and Lee. This work is published and licensed by Dove Medical Press Limited. The full terms of this license are available at https://www.dovepress.com/terms.php BY NC and incorporate the Creative Commons Attribution - Non Commercial (unported, v3.0) License (http:///creativecommons.org/licenses/by-nc/ $3.0 /$ ). By accessing the work you
hereby accept the Terms. Non-commercial uses of the work are permitted without any further permission from Dove Medical Press Limited, provided the work is properly attributed. For permission

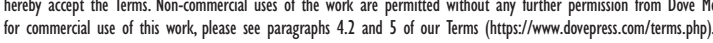


The HRQOL should be considered as an important index of effective health care as it can give a more holistic view of well-being. ${ }^{9}$ However, there is very little published work on evaluation of HRQOL in thalassemia patients. ${ }^{10,11}$ It is believed that the HRQOL in thalassemia patients is lower than that of normal population because of a variety of issues like the presence of comorbid conditions, frequent hospital visits for transfusion, painful injections, appearance, absence of sexual development, infertility, inability to take care of their own family, disease complications, uncertainties about the future, psychiatric disorders, and difficulties in employment and playing a role in society. ${ }^{12}$

A 36-Item Short Form Health Survey (SF-36) and its derivative were the most commonly used instrument to measure HRQOL in adult thalassemia patients. It may, however, be insensitive to the unique experience of thalassemia patients. ${ }^{11}$ In 2012, Specific Thalassemia Quality of Life Instrument (STQOLI) was developed and had been validated for use among the patients in Greece. ${ }^{11}$ So far, it is the only instrument that is tailored specifically for the adult thalassemia patients.

This study attempted to replicate the psychometric structure of the original STQOLI using the Malay version of the instrument.

\section{Material and methods}

\section{Participants and settings}

This cross-sectional study was conducted among adult beta thalassemia patients who received transfusion treatment at the Thalassemia Treatment Centre (TTC) in Queen Elizabeth Hospital from February to July 2015. Queen Elizabeth Hospital is a referral tertiary hospital located in Kota Kinabalu, the capital city of Sabah. The inclusion criteria were patients diagnosed with beta thalassemia and aged 18 years and above. The exclusion criteria were patients who do not understand Malay language or unwilling to participate in the study. The eligible patients were identified from the list of patients who received their transfusion treatment at the TTC. Eighty-two participants were conveniently selected during the transfusion day. The participants were justified as representative of all Sabah beta thalassemia patients as TTC caters not only for patients from Kota Kinabalu but also patients from other districts in Sabah. The study has been approved by Medical Research and Ethics Committee (MREC) of Malaysia.

\section{Study instrument}

In this study, HRQOL assessment was performed using the Malay version of STQOLI. ${ }^{11}$ A user agreement was signed with the copyright owner of the original STQOLI,
Dr Georgios Lyrakos, from the Lyrakos G. Psychometrics and Research, Greece, prior to the use of the questionnaire.

The questionnaire consists of four domains: disease and symptoms (12 items), chelation therapy (13 items), psychosocial impact (10 items), and transfusion impact (5 items). The HRQOL was assessed by patient response in each domain. Both overall HRQOL and subscales were measured with a scale from 0 to 100 , with higher values indicating better quality for each scale.

The translation of the English version STQOLI into the Malay version was done by the International Translation Network, a translating agency, using the forward-translation and back-translation. The content validity of the questionnaire was confirmed by the chief hematologist of the hospital.

\section{Data collection}

All eligible patients were approached as they came in for routine follow-ups at the TTC. Written informed consent was obtained prior to participation in the study. The administration of the questionnaire was done either via a face-to-face guided interview for those who cannot read or self-administration for those who can read. For the interview, the questions were read out word-by-word from the questionnaire and their responses were recorded. Only one trained interviewer was assigned for the interview.

\section{Data analysis}

Data were analyzed by IBM SPSS version 20.0 (IBM Corporation, Armonk, NY, USA). The sampling adequacy was assessed by Kaiser-Meyer-Olkin Measure of Sampling Adequacy. The internal structure of the questionnaire was assessed by principal component analysis with an orthogonal (varimax) rotation. Variables with eigenvalue more than 1 and factor loading more than 0.4 were retained. The reliability of the questionnaire was assessed by Cronbach's alpha coefficient. The participants' characteristics were presented by descriptive statistics.

\section{Results}

Eighty-two out of 147 thalassemia major patients aged 18 years and above were included in the study (56\% participation rate). The reasons for exclusion were unable to understand the questions in Malay language (63 patients) and unwillingness to participate ( 2 patients). The participants' characteristics are shown in Table 1. The appropriateness of the factor analysis was assessed by the Kaiser-MeyerOlkin Measure of Sampling Adequacy. The Kaiser-MeyerOlkin Measure of Sampling Adequacy was 0.635, which is acceptable. ${ }^{13}$ The Cronbach's alpha coefficient for the total 
Table I Demographic data of the participants $(n=82)$

\begin{tabular}{lll}
\hline & Frequency (\%) & Mean (SD) \\
\hline $\begin{array}{l}\text { Age (years) } \\
\text { Sex }\end{array}$ & & \\
$\quad$ Male & $42.4(4.2)$ \\
$\quad$ Female & $40(48.8)$ & \\
Iron chelation & & \\
$\quad$ Oral pill only & $21(25.6)$ & \\
Subcutaneous only & $3(3.7)$ & \\
Combination & $58(70.7)$ & \\
Level of education & \\
$\quad$ No formal education & $8(9.8)$ & \\
Primary & $13(15.9)$ & \\
Secondary & $49(59.8)$ & \\
Tertiary & $12(14.8)$ & \\
Residence & $21(25.6)$ & \\
Inside Kota Kinabalu & $61(74.4)$ & \\
Outside Kota Kinabalu &
\end{tabular}

Note: aPrimary is years $7-12$, secondary is years $13-17$, tertiary is university program.

Abbreviation: SD, standard deviation.

scale was 0.913 , which is excellent. ${ }^{13}$ The factors, loadings and factors' labels after rotation are shown in Table 2. The analysis identified 12 factors accounting for $72.2 \%$ of the variance. The first factor accounted for the largest variance at $24.2 \%$ and the twelfth factor accounted for the smallest variance at $2.6 \%$. Only eight factors were interpretable. The eight factors were "iron chelation pump impact" (component 1: q7, q29, q51, q25, q28, q8, q6), "transfusion impact" (component 2: q43, q45, q17, q44), "time spent on treatment and its effect on work and social life" (component 3: q46, q47, q20, q19, q50, q16), "sex life" (component 4: q39, q38, q36), "side effects of treatment" (component 5: q9, q34, q30), "cardiovascular problems" (component 6: q35, q32, q33), "psychology" (component 8: q2, q48, q49), and "iron chelation pill impact" (component 9: q12, q14). The scale reliability of each interpretable factor was assessed by Cronbach's alpha, with value 0.7 and higher was considered acceptable. ${ }^{13}$ The Cronbach's alpha was highest for component 1 ("iron chelation pump impact") at 0.847 and lowest for the component 8 ("psychology") at 0.592 . The factors with Cronbach's alpha less than 0.7 were the component 8 ("psychology") and the component 6 ("cardiovascular problems"). The Cronbach's alpha of the component 6 ("cardiovascular problems") and the component 4 ("sex life") can be improved by removing q33 (I feel fatigue when I have low hemoglobin) and q36 (splenectomy affects me negatively), respectively, both of which were irrelevant to the factors they belong to.

\section{Discussion}

The best HRQOL instrument is the one that shows consistent internal validity and constructs across different populations.
The replicability of factor structure of an instrument can be demonstrated by using the exploratory factor analysis. In this application, strong replication across cultures and languages not only confirms the goodness of the translations of the instrument, but also the universality of the factor structure. Without a reasonable likelihood of replicability, the researchers have little reason to use a particular scale of the instrument. ${ }^{14}$

The purpose of this study was the adaptation and validation of the Malay version of the STQOLI. The STQOLI is a tool that specifically measures the quality of life of adult thalassemia major patients. This study was unable to replicate the internal structure of the Greek version of the STQOLI (Table 3) in the Sabah's adult thalassemia patients. While exhibiting a different internal structure than the Greek version, the Malay STQOLI has the potential to be modified into a good tool to measure the quality of life of the adult thalassemia major patients in this region.

In comparison to the study by Lyrakos et al, ${ }^{11}$ our sample was younger (mean age 23.4 vs 37.2 years), consisted of more males (51.2\% vs $26.6 \%$ ), less educated ( $14.8 \%$ vs $51.6 \%$ with tertiary education), and none of them were married ( $0 \%$ vs $37.5 \%$ married). The differences in these cultural constructs especially the education level may explain in part the variation in the internal structures between the two studies.

The difference in structure can also be attributed to the ambiguity of the purported factors described by Lyrakos et al, ${ }^{12}$ which can be interpreted in many ways. For example, the study showed that the Greek thalassemia patients were able to distinguish between the concepts of "pain" (q28, q29) and "chelation impact of iron chelation pump" (q51, q6, q8, q7, q15). The Sabah's thalassemia patients, meanwhile, treated "pain" as part of the latter concept and were logically not wrong. Another notable example was that the Greek patients treated items about time spent for treatment (q46, q47) as a different concept from items about social and work life (q20, q19, q16). The Sabah's patients, however, seemed to think that the social and work life and time spent for treatment were indistinguishable.

It must also be mentioned that the Greek version of STQOLI was originally designed for self-administration. In our study, some participants need to be interviewed in answering the questionnaire due to the low literacy level. This may inadvertently affect the results of the study as the participants might not respond truthfully because they might wish to present themselves in acceptable manner. Meanwhile, the importance of literacy for self-reported health-related quality of life was highlighted by Cassis et al. ${ }^{15}$ It was reported that education level was not found to be a helpful criterion and thus an assessment of literacy level should be conducted 


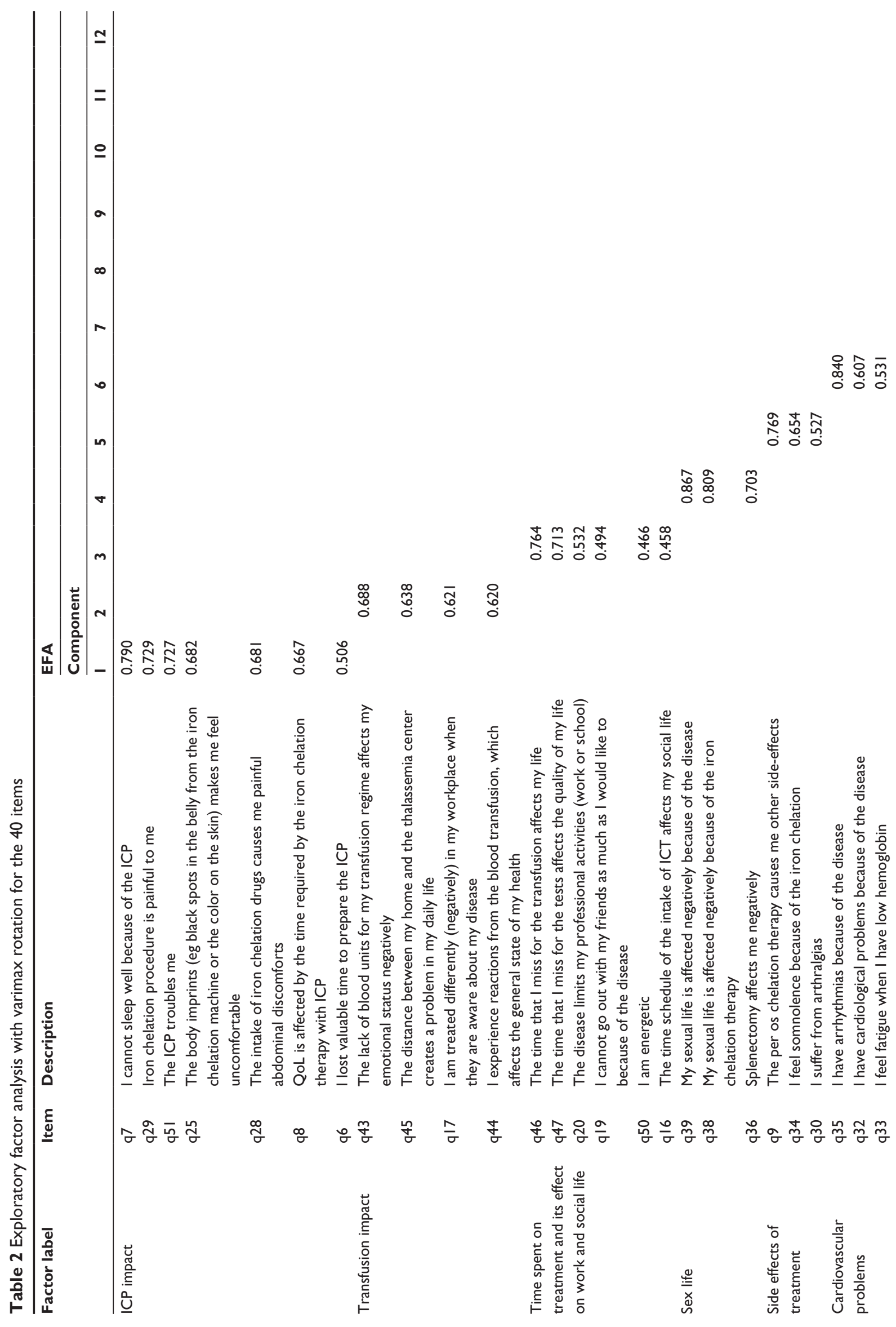




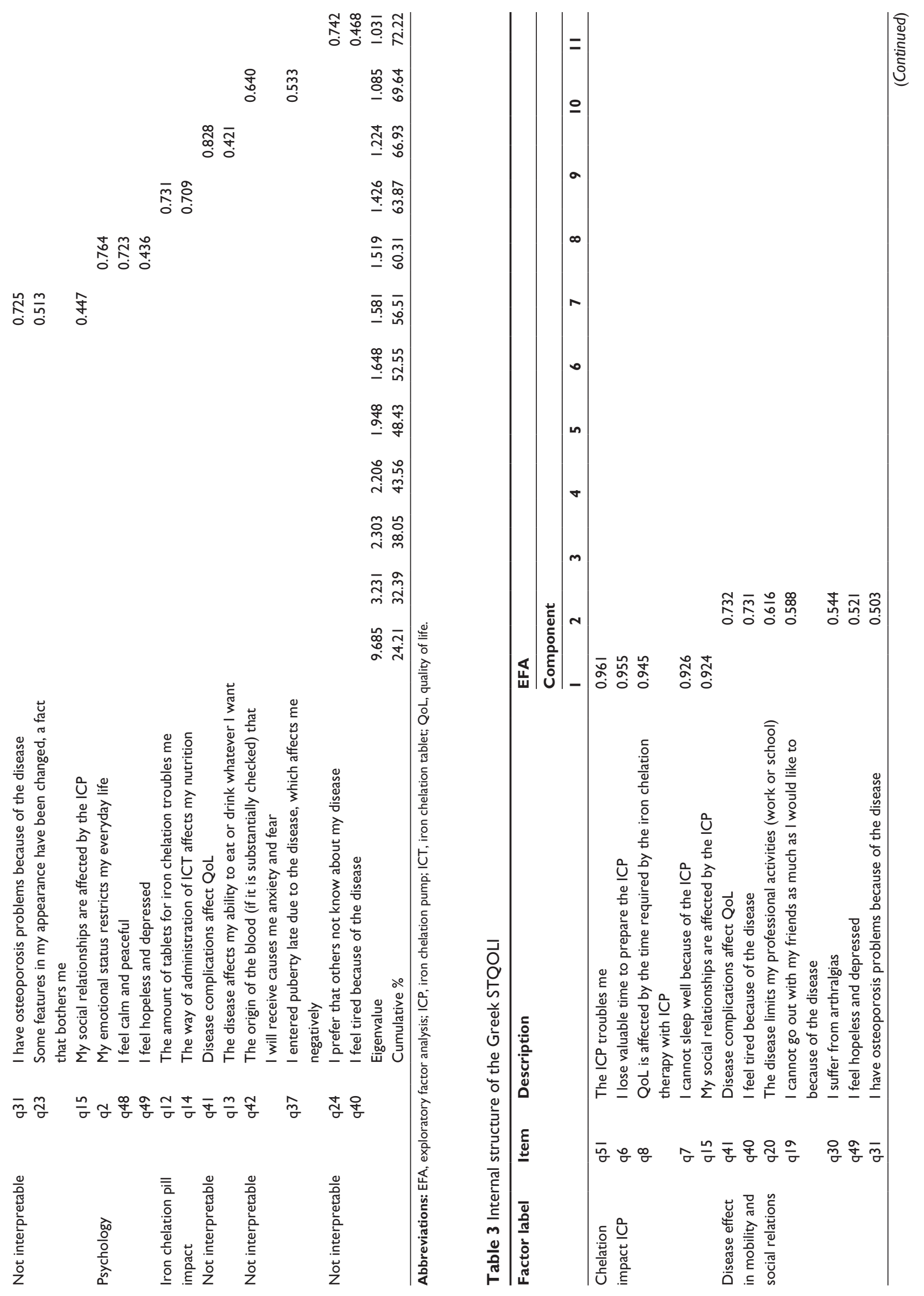




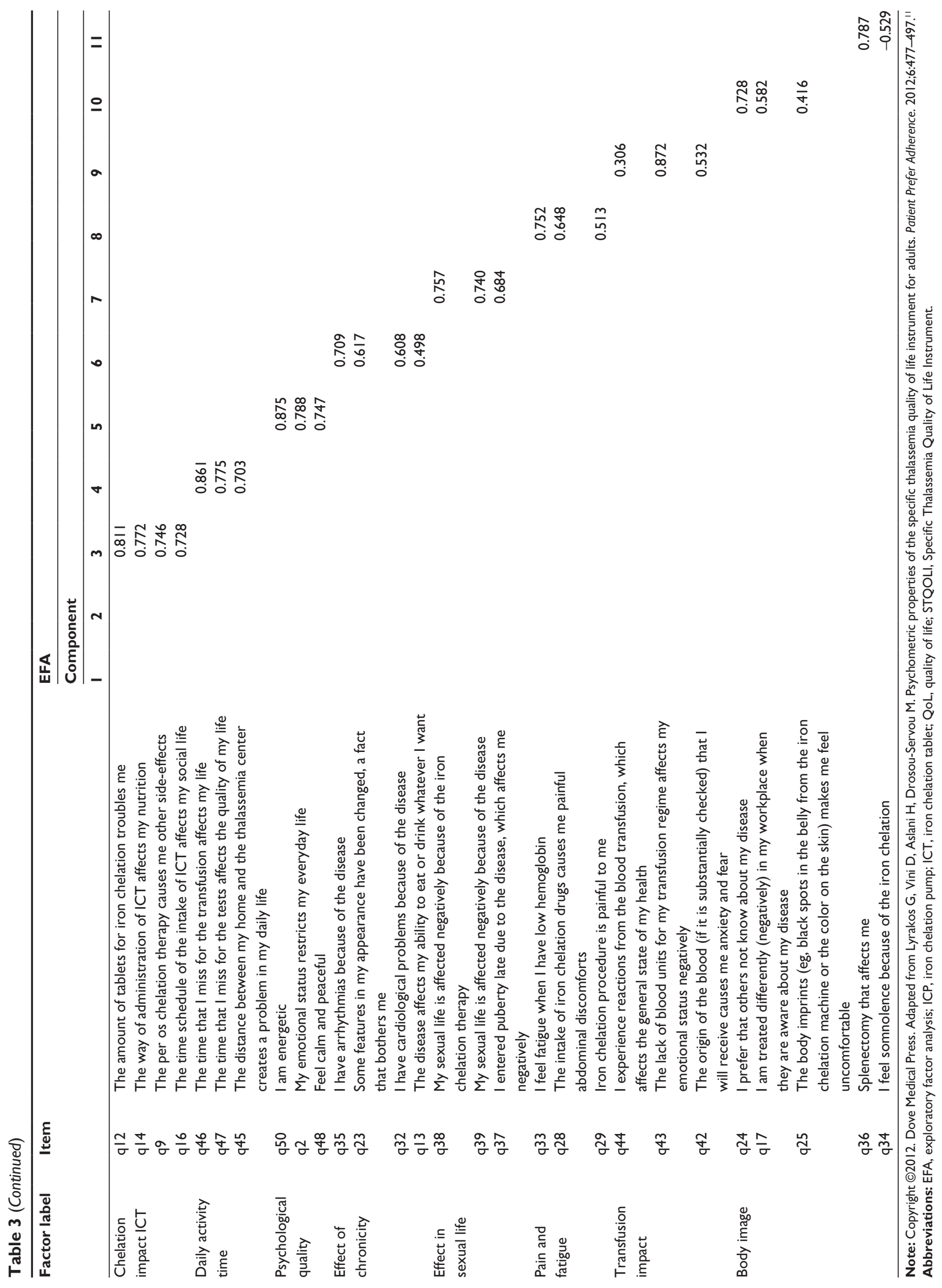


prior to recruitment and those with limited literacy should be assisted to ensure the comprehension of the questions. ${ }^{15}$

The results of this study showed that the Malay version of STQOLI needs to be modified to suit the local population. The modification of the questionnaire should be based on the eight interpretable factors found in this study. Furthermore, concurrent validity should also be examined in future research. This can be done by administering another quality of life tool together with the modified instrument and the correlation between the two instruments should be assessed. One notable limitation of this study was the small sample size. This, however, was unavoidable as many of the thalassemia patients in Sabah are illiterate and had to be excluded from the study.

\section{Conclusion}

This study was unable to replicate the internal structure of the Greek STQOLI in Sabah's adult thalassemia patients. Instead, a new structure has emerged that can be used as a guide to develop a HRQOL questionnaire specific for adult thalassemia patients in Sabah. Future research in this area should focus on the eight factors identified from this study.

\section{Acknowledgments}

We would like to thank Dr Georgios Lyrakos from the Lyrakos G. Psychometrics and Research, Greece for the permission to use the STQOLI in this study. We would also like to thank the Director General of Health Malaysia for permission to publish the results of this study.

\section{Author contributions}

All authors contributed toward data analysis, drafting and critically revising the paper and agree to be accountable for all aspects of the work.

\section{Disclosure}

The authors report no conflicts of interest in this work.

\section{References}

1. Muncie HL, Campbell J. Alpha and beta thalassemia. Am Fam Physician. 2009;80(4):339-344.

2. George E, Jamal AR, Khalid F, Osman KA. High performance liquid chromatography (HPLC) as a screening tool for classical beta-thalassaemia trait in Malaysia. Malays J Med Sci. 2001;8(2):40-46.

3. Guidelines Development Group. Management of Transfusion Dependent Thalassaemia. 1st ed. Putrajaya: Ministry of Health Malaysia; 2009.

4. Teh KL, George E, Lai MI, Tan JAM, Wong L, Ismail P. Molecular basis of transfusion dependent beta-thalassemia major patients in Sabah. J Hum Genet. 2014;59:119-123.

5. Caocci G, Efficace F, Ciotti F, et al. Health related quality of life in Middle Eastern children with beta-thalassemia. BMC Blood Disord. 2012;12(6):1-7.

6. Thavorncharoensap M, Torcharus K, Nuchprayoon I, Riewpaiboon A, Indaratna K, Ubol B. Factors affecting health-related quality of life in Thai children with thalassemia. BMC Blood Disorders. 2010;10(1): $1-10$.

7. Gollo G, Savioli G, Balocco M, et al. Changes in the quality of life of people with thalassemia major between 2001 and 2009. Patient Prefer Adherence. 2013;7:231-236.

8. Baghianimoghadam MH, Sharifirad G, Rahaei Z, Baghianimoghadam B, Heshmati $\mathrm{H}$. Health related quality of life in children with thalassaemia assessed on the basis of SF-20 questionnaire in Yazd, Iran: a case-control study. Cent Eur J Public Health. 2011;19(3):165-169.

9. Telfer P, Constantinidou G, Andreou P, Christou S, Modell B, Angastiniotis M. Quality of life in thalassemia. Ann N Y Acad Sci. 2005; 1054:273-282.

10. Azarkeivan A, Hajibeigi B, Alavian SM, Lankarani MM, Assari S. Associates of poor physical and mental health-related quality of life in beta thalassemia-major/intermedia. J Res Med Sci. 2009;14(6):349-355.

11. Lyrakos G, Vini D, Aslani H, Drosou-Servou M. Psychometric properties of the specific thalassemia quality of life instrument for adults. Patient Prefer Adherence. 2012;6:477-497.

12. Haghpanah S, Nasirabadi S, Ghaffarpasand F, et al. Quality of life among Iranian patients with beta-thalassemia major using the SF-36 questionnaire. Sao Paulo Med J. 2013;131(3):166-172.

13. Coakes SJ. SPSS Version 20.0 for Windows Analysis without Anguish. 1st ed. Australia: John Wiley \& Sons Australia Ltd; 2013.

14. Osborne JW, Fitzpatrick DC. Replication analysis in exploratory factor analysis: what it is and why it makes your analysis better. PARE. 2012;17(15):1-8.

15. Cassis FR, Carneiro JD, Villaca PR, et al. Importance of literacy for self-reported health-related quality of life: a study of boys with haemophilia in Brazil. Haemophilia. 2013;19(6):866-869.
Patient Preference and Adherence

\section{Publish your work in this journal}

Patient Preference and Adherence is an international, peer-reviewed, open access journal that focuses on the growing importance of patient preference and adherence throughout the therapeutic continuum. Patient satisfaction, acceptability, quality of life, compliance, persistence and their role in developing new therapeutic modalities and compounds to optimize

\section{Dovepress}

clinical outcomes for existing disease states are major areas of interest for the journal. This journal has been accepted for indexing on PubMed Central. The manuscript management system is completely online and includes a very quick and fair peer-review system, which is all easy to use. Visit http://www. dovepress.com/testimonials.php to read real quotes from published authors. 